\title{
Elusive to the end
}

$\mathrm{M}$ exican artist Frida Kahlo had an operation in 1946 to fuse four vertebrae with a metal rod and a piece of bone extracted from her pelvis. Months later, she was still in constant pain, suffered from depression and paranoia, was drinking heavily and popping painkillers.

At this time, the suicidal, violent Kahlo started seeing a psychiatrist, becoming the first woman in Mexico to undergo psychoanalysis, according to Martha Zamora, author of Frida Kahlo: The Brush of Anguish.

Psychiatrist Ramon Parres certainly faced a challenge. Physically, Kahlo suffered from the effects of childhood polio and a horrific, bone-crushing trolley accident while a teenager. Psychologically, she had been troubled since adolescence by gender and ethnicity issues. Her marriage to superstar artist Diego Rivera was an emotional rollercoaster. And one can only guess how long it took Parres to realize Kahlo often played loose with the truth.

Did Dr. Parres ever really know Frida Kahlo? Has anybody since?

Fifty-eight years after Kahlo's death, the world is still trying to psychoanalyze or at least understand the enigmatic woman who has become a feminist icon and Mexico's most famous artist. The latest attempt at re-examination is an exhibition at the Art Gallery of Ontario in Toronto, Frida and Diego: Passion, Politics and Painting, which continues until Jan. 20, 2013 before moving to Atlanta, Georgia.

Fans of the two artists have the rare opportunity to see 80 of their paintings. Usually, we are lucky to get two or three at a time. That fact alone makes this show a triumph, even though the exhibition theme seems rather forced. It tries to link the two artists' work to their joint commitment to revolutionary politics and pride in

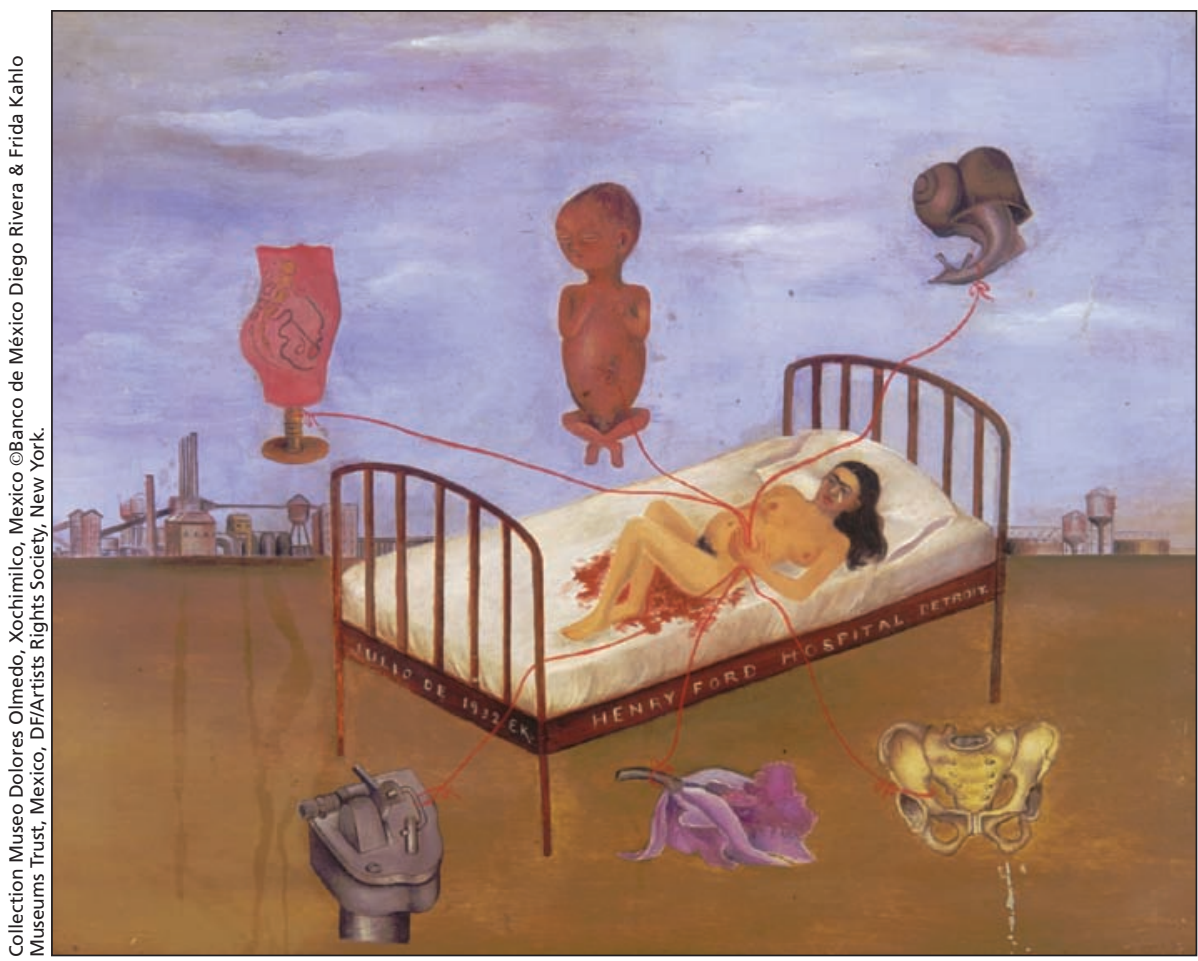

Henry Ford Hospital, 1932, by Frida Kahlo (1907-1954). Oil on metal, 31 x $38.5 \mathrm{~cm}$.

Mexico's mixed race "mestizo" culture. The same could be said of almost any two Mexican artists from the first half of the 20th century. Clearly, the emphasis in Toronto is on showmanship, not scholarship.

Most museums in Mexico and abroad tend to mount separate exhibitions of the two artists because their work is perceived to be so different. Rivera is best known for politically charged murals and Kahlo for her very personal, often surrealist self-portraits chronicling her pain, sorrow and medical procedures.

Kahlo's torments are very evident in her paintings chosen by curators Dot Tuer and Elliot King mainly from private collections in Mexico. Kahlo's works each come with a harrowing narrative spun by the artist before her death. But can those narratives be believed? As Tuer points out, Kahlo and Rivera were both "fabulists" inventing their life stories to suit carefully constructed plots. Kahlo, for example, gave her birthdate as 1910, three years after the real date, so she could say she was born at the beginning of the Mexican Revolution. And then there are the narratives surrounding her supposed infertility.

We see in Toronto one of Kahlo's most famous paintings, Henry Ford Hospital, 1932. It shows the artist in a Detroit hospital bed, nude and bleeding after a miscarriage. Hovering above her is the male fetus she lost. Kahlo liked to give the impression that she wanted, more than anything, to have a child by Rivera, who had offspring from previous relationships. The truth may be different.

"In fact Frida's correspondence reveals that she had abortions for unwanted pregnancies before and after the medical crisis in Detroit and she 
was perfectly aware that Diego did not want another child," says Zamora.

A lesser known Kahlo work in the exhibition is a lithograph, Frida and

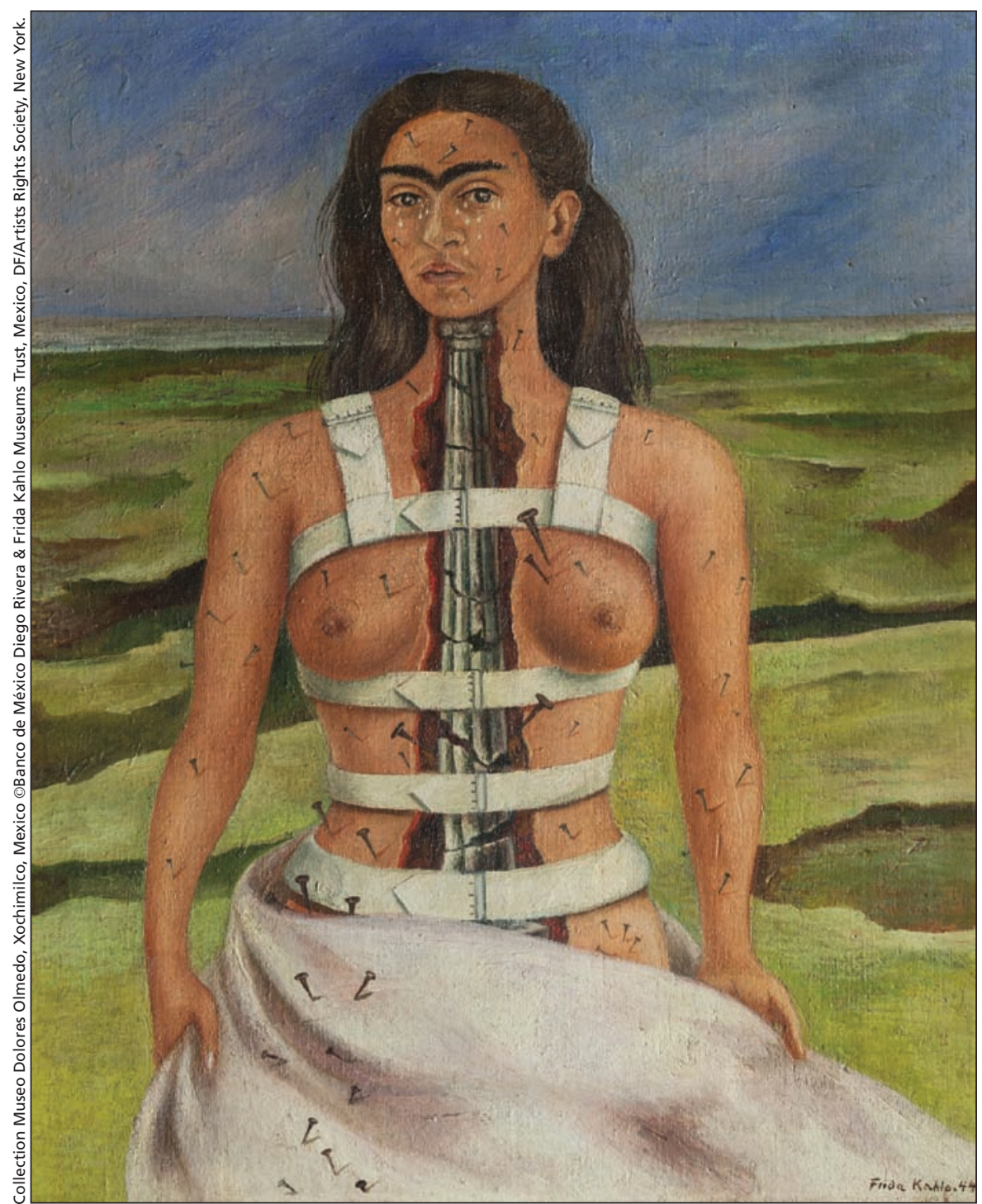

The Broken Column, 1944, by Frida Kahlo (1907-1934). Oil on canvas, 39.8 x $30.5 \mathrm{~cm}$. the Abortion, 1932 showing the artist nude and standing. A fetus is on the ground before her. Tears flow from Kahlo's eyes and genitals. Clearly,
Kahlo had mixed emotions about abortion.

And how should we take Kahlo's painting, A Few Small Nips, 1935? A nude woman lies twisted and bloody on a bed. Beside her stands the man who killed her. This painting is believed to have been inspired by a newspaper story about a murderous husband but may also symbolize Kahlo's distress upon learning Rivera was having an affair. So, is Kahlo the feminist expressing solidarity with abused women or merely illustrating the pain from a duplicitous lover? Take your pick.

One of Kahlo's most powerful paintings, The Broken Column, 1944, thankfully made it to Toronto. Kahlo is dressed only in a medical corset. Her chest is open to reveal her spine is a broken Ionic column. Her skin is embedded with nails. She weeps at the pain that drove her to drink, drugs and Parres.

Parres was with Kahlo at the end. The psychiatrist signed her death certificate on July 13, 1954, listing the cause of death as a pulmonary embolism, although no postmortem was performed. Research by biographer Zamora points to a possible suicide or an accidental overdose of drugs and alcohol.

So, what's the truth? Parres is deceased so we can speculate and feed whatever narrative suits us. The truth of Kahlo's life and her death remains elusive.

\section{Paul Gessell}

Art critic

Ottawa, Ont.

CMAJ 2013. DOI:10.1503/cmaj.121761 